\title{
HYDROGEN TRAPPING IN MOLYBDENUM IN THE PRESENCE OF RADIATION DAMAGE
}

\author{
A.L. HANSON * and D.H. VINCENT \\ Department of Nuclear Engineering, University of Michigan, Ann Arbor, Michigan 48109, USA \\ C.N. DAVIDS \\ Physics Division, Argonne National Laboratory, Argonne, Illinois 60439, USA
}

Received 20 July 1980 ; in revised form 28 January 1981

\begin{abstract}
Hydrogen was implanted in samples of single crystal molybdenum, many of which had been previously damaged by ${ }^{4} \mathrm{He}$ at 18 or $150 \mathrm{keV}$. The hydrogen implantations were at low energies, usually at $10 \mathrm{keV}$. Depth protiles (up to $200 \mathrm{~nm}$ ) of the trapped hydrogen were obtained using the nuclear reaction ${ }^{1} \mathrm{H}\left({ }^{19} \mathrm{~F}, \alpha \gamma\right)^{16} \mathrm{O}$. A comparison of the trapping efficiency per dpa for both high and low helium concentrations, realized by the 18 and the $150 \mathrm{keV}{ }^{4} \mathrm{He}$ implant, respectively, indicates that the presence of the implanted helium contributes to the trapping of hydrogen, possibly through the inhibition of damage annealing.
\end{abstract}

\section{Introduction}

The interactions of hydrogen with metals and alloys can result in the cracking, embrittlement, and failure of the host material $[1,2]$. Impurities and defects can influence the normal motion of the hydrogen through metal lattices by providing traps for the hydrogen. Ion implantation provides a unique means to study these hydrogen-trap interactions since the levels of defects and impurities can be controlled by selection of the ion-energy combinations.

The analysis of hydrogen in materials has traditionally been a rather complicated undertaking. Hydrogen is an extremely common element so contamination is a major problem. In addition, more traditional elemental analysis techniques such as neutron activation analysis, Auger electron spectroscopy, $\mathrm{X}$-ray analysis, ESCA, and others are not sensitive to hydrogen. In 1973, Leich and Tombrello [3] reported studying hydrogen in lunar materials with a 16.0-17.5 MeV fluorine-19 beam utilizing the ${ }^{1} \mathrm{H}\left({ }^{19} \mathrm{~F}, \alpha \gamma\right)^{16} \mathrm{O}$ reaction. Since this reaction has a strong, narrow resonance at $16.44 \mathrm{MeV}$, they were

\footnotetext{
* Present address: Physics Department, Brookhaven National Laboratory, Upton, L.I., New York 11973, USA.
}

able to obtain a "profile" of the hydrogen in the sample, that is, the hydrogen concentration as a function of depth. Many experimenters since then have used this and other reactions to study hydrogen and deuterium in the near surface regions (usually the first few 100 nanometers) of samples [4-8].

Some of the earlier experiments on hydrogen trapping in metals in the presence of radiation damage were performed by Erents and McCracken $[9,10]$. They implanted deuterium in nickel and molyb-denum and found that the rate of release of the deuterium was lower than when the deuterium was introduced by diffusion. This indicated that the defects produced by the deuterium implantation provided traps for the deuterium. Picraux et al. $[11,12]$ and $B \phi t t i g e r$ et al. [6] then studied enhanced trapping of deuterium and hydrogen implanted in samples of single crystal molybdenum and niobium that had been previously damaged with 11 and 18 $\mathrm{keV}$ helium, $55 \mathrm{keV} \mathrm{Ne}^{+}$, and $55 \mathrm{keV} \mathrm{Bi}^{+}$. They reported total trapping efficiencies for the trapped deuterium and relative depth distributions for the trapped hydrogen. As the deuterium concentration was increased the amount trapped was found to reach a saturation, the level depending on the predamage ion species and its fluence. It was also determined 
that the lighter ions trap hydrogen more effectively per initial displacement than the heavier ions. The authors concluded that the hydrogen trapping was due to defect trapping and not chemical binding with the implanted impurities. However, the implanted impurities can interact with defects forming impurity-defect complexes. This means that the impurities may well play an important role in the trapping of hydrogen. The intent of the present study was to explore the contribution of implanted helium to the trapping of hydrogen. To this end samples were predamaged with helum ions of two different energies. The implantation doses were adjusted such that roughly the same amoun of damage energy would be deposited in the region of interest while the helium atom concentration would vary significantly.

\section{Experimental methods and data evaluation}

The nuclear reaction

${ }^{1} \mathrm{H}\left({ }^{19} \mathrm{~F}, \alpha \gamma\right)^{16} \mathrm{O}$

has been used to analyze hydrogen trapped in single crystal molybdenum samples, many of which had been previously damaged by the implantation of $1 \times 10^{16} \mathrm{He} / \mathrm{cm}^{2}$ at $18 \mathrm{keV}$ or $6 \times 10^{16} \mathrm{He} / \mathrm{cm}^{2}$ at $150 \mathrm{keV}$. The hydrogen was also introduced by ion implantation at 10,15 , and $20 \mathrm{keV}$ to doses between $1 \times 10^{16} \mathrm{H} / \mathrm{cm}^{2}$ and $6 \times 10^{16} \mathrm{H} / \mathrm{cm}^{2}$. A 150 kV Series 9400 Texas Nuclear Cockcroft--Walton neutron generator which had been modified for use in ion implantation experiments was employed for the acceleration of both the hydrogen and helium. The accelerator was pumped with a cold-trapped diffusion pump. The vacua for the ion pumped implantation target chamber ranged between $8 \times 10^{-5}$ and $13 \times$ $10^{-5} \mathrm{~Pa}$ during the implantations.

The targets were $64 \mathrm{~mm}$ diameter discs of single crystal molybdenum with the $(001)$ channeling direc. tion $10 \pm 1^{\circ}$ from the surface normal. The implan. tations were within one degree of the surface normal. All of the samples were sliced from the same rod of a single crystal molybdenum with a Norton wafering machine. They were mechanically polished to $1 \mu \mathrm{m}$ and then electropolished. The surface finish was checked with a scanning electron microscope.

The hydrogen concentrations were measured with a Tuorine-19 beam from the FW tandem $\mathrm{Yan}$ de Graaff accelerator at Argona National Laboratory and the EN tandem Van de Graff at Wostem Mich gan University. The targets were nounted on a move. able "ladder" [13] and were oriented $90 \pm 1^{\circ}$ to the beam. One of the positions had a hole drilled though the ladder the size of the samples. In this way the beam could be sent through the chamber to a beam dump $3 \mathrm{~m}$ away. This arrangement facilitated the aignment of the beam in addition to the removal of the proper background radiation, since gamma rays will be emitted from beam-structural material (espe cially collimator) interactions. The vacuum during analysis was usually in the low tomid. $10^{-4}$ Pa range. The system was pumped with a coldutraped diffu. sion pump. A coaxial, liquid nitrogen-cooled cold finger was mounted $2 \mathrm{~cm}$ from the sample.

The fluorine 19 beam energies varied between 16.4 and $17.5 \mathrm{MeV}$ making use of the $16.44 \mathrm{MeV}$ ( energy resonance for gamma-ray production. This resonance has a width of $90 \pm 4 \mathrm{keV}$ and peaks at $540 \mathrm{mb}[14,15]$. The gamma rays detected were the 6.1-, 6.9-, and 7.1-MeV gamma rays from the deexcitation of the residual ${ }^{16}$ O nucleus. Fig. 1 shows a plot of the cross section for the production of these three gamma rays at $90^{\circ}$, the geometry used in this experiment. These data were provided by Amsel et at. [16].

Since the cross section is not zero in the off-reson. ance region (around the 16.44 MeV rescnance) of the excitation function, a simple proportionality in general cannot be assumed between the gamma-ray yields as a function of energy and the hydrogen con *

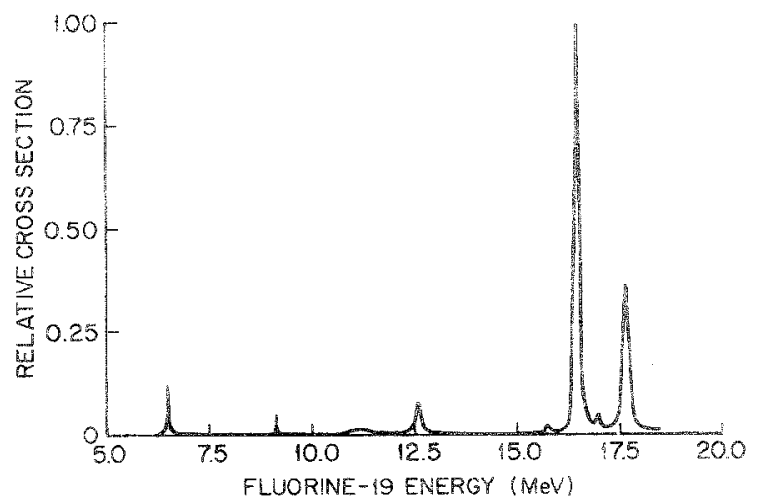

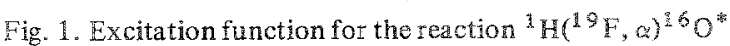


centration as a function of depth. Therefore, a histogram technique originally discussed by Clark et al. [7], has been used for unfolding the experimental data. This technique has been modified to account for changing surface contamination and for spread in the beam energy as the beam slows down in the sample [13]. The histogram segments were chosen to be $30 \mathrm{~nm}$ wide centered around the data point. Usually no more than nine data points were analyzed together. Because of the large surface contamination, the data between the surface and $40 \mathrm{~nm}$ is not reported. Only the region up to $200 \mathrm{~nm}$ was characterized since beyond that the next $\mathrm{H}(\mathrm{F}, \alpha \gamma)^{16} \mathrm{O}$ resonance begins to interact with the surface hydrogen. The maximum angular divergence of the fluorine beam in the region of interest was about $1^{\circ}$.

\subsection{Surface contamination layer buildup}

One of the major problems associated with the data analysis in this experiment is the presence of a large hydrogen contamination layer on the surface of the sample. This contamination is caused by molecular hydrogen and hydrocarbons (such as pump oil) adhering to the surface of the sample [17]. The amount of contamination depends on the type of sample, the pressure in the vacuum system, the current of the fluorine beam and the amount of beam that has struck the target. This problem is inherent to the analysis of hydrogen and not a problem only associated with the experiment being described $[6,7,17]$.

The thickness of the hydrogen contamination layer was determined to be extremely thin, namely only a few atom layers at most. This was determined by measuring the effective resonlance width on all of the samples, both with and without measurable hydrogen in the first $200 \mathrm{~nm}$. The observed width was on the order of the actual width of the resonance. The gamma-ray yield associated with the surface peak was roughly six times the gamma ray yield obtained when the concentration in the sample was five atom percent.

Since the contamination was large compared to the hydrogen within the samples, the off-resonance reactions with this contamination layer often interfered significantly with the gamma-ray yields of interest. This problem was enhanced by the fact that the contamination layer changed during analysis. The changing contamination layer was studied with multiple measurements of the gamma-ray yields associated with the first histogram segment, defined by a beam energy of $16.45 \mathrm{MeV}$. The contamination was found to increase rapidly at first and then level off to a saturation after roughly $6 \times 10^{14}$ particles $/ \mathrm{cm}^{2}$ were collected. In order to account for this buildup, it was assumed that the first histogram segment changed as

$h_{1}=h_{10}+Q w$.

In this equation, $h_{1}$ is the instantaneous concentration, $h_{10}$ the concentration at the beginning of anal$y$ sis, $w$ the buildup factor (a constant) and $Q$ some beam dependent quantity, usually cumulative collected charge. Ignoring changes in the surface contamination layer resulted in errors as great as $25 \%$ for some of the points in the distribution [13].

\subsection{Beam spread correction}

When a beam of monoenergetic ions passes through a thickness $\Delta x$ of a sample, the ions will suffer an energy loss, which for this experiment, can be expressed as

$\Delta E \cong \Delta x(\mathrm{~d} E / \mathrm{d} x)$.

This expression is valid when the stopping power does not change appreciably over the energies of interest, which was the case in this experiment.

Since this energy loss is a statistical process, a spread in the energy will occur. This spread is usually assumed to follow a Gaussian distribution:

$\frac{N(E) \mathrm{d} E}{N}=\frac{1}{\sqrt{ }\left(2 \pi \alpha^{2}\right)} \exp \left(-\frac{\left(E-E_{0}\right)^{2}}{2 \alpha^{2}}\right) \mathrm{d} E$,

where $E$ is any energy less than the incident energy $E_{\mathrm{i}}, E_{0}$ is the mean energy equal to $E_{\mathrm{i}}-\Delta E$, and $\alpha^{2}$ is the variance. (See [18] and [19] for expressions for $\alpha^{2}$ )

This spread in the beam energy will have an effect on the cross section for the nuclear reaction, so the effective cross section at every "point" in the sample * and for every incident energy is recalculated by

\footnotetext{
* These "points" within the sample from the surface were determined by the energy increments of the excitation function data provided by Amsel et al. [16] coupled with eq. (3).
} 
numerically integrating:

$\sigma\left(E_{0}\right)=\frac{1}{\sqrt{\left(2 \pi \alpha^{2}\right)}} \int_{E_{\mathrm{i}}}^{0} \sigma(E) \exp \left(-\frac{\left(E-E_{0}\right)^{2}}{2 \alpha^{2}}\right) \mathrm{d} E$.

This effective cross section is then used in the histogram unfolding technique. The beam spread correction is usually within $5 \%$ of the values when the correction is not used. Of course, the magnitude of the correction increases with depth.

\subsection{Absolute calibration}

The calibration of the hydrogen concentrations was made by comparison with samples of Lexan polycarbonate. The uncertainty in the calibration is difficult to assess. In order to make this comparison, the stopping power for the fluorine ions incident on the Lexan must be calculated from data from the Northcliffe and Schilling tables [20] with the "Bragg rule" for the additive property of stopping powers of compounds [21]:

$S^{A}{ }_{n n} B_{n}=m S^{A}+n S^{B}$.

The uncertainty in the stopping power values of the $\mathrm{N}$ and $\mathrm{S}$ tables is unknown for fluorine incident on carbon, hydrogen and oxygen.

\section{Experimental results}

Table 1 represents a compilation of data on the various helium and hydrogen implantations administered to moiybdenum samples it the course of this study. The data are arranger in three groups accoding to the anount and energy of henm implanted before the hydrogen implantations: to He pre-implantation, $18 \mathrm{keV}$ Hewmplantation of $1 \times$ $10^{16} \mathrm{He} / \mathrm{cm}^{2}$ and $150 \mathrm{keV}$ He-implantation of $\mathrm{s} x$ $10^{16} \mathrm{He} / \mathrm{cm}^{2}$. The hydrogen profiles obtained ase presented in this order in sections $3.2,3.4$ and 3.5 .

\subsection{Analysis of blank samples}

In order to be convinced that the observed hydrogen distributions were due to implanted hydrogen and not to the surface contamination ror the bulk hydrogen, several samples were analyzed with neither hydrogen nor helium implanted in them. In addition, two samples were implanted only with helium, one at $18 \mathrm{keV}$ to $1 \times 10^{36} \mathrm{He} / \mathrm{cm}^{2}$ and one at $150 \mathrm{keV}$ to $8 \times 10^{16} \mathrm{Ke} / \mathrm{cm}^{2}$. For all of these samples the hydrogen concentrations were found to be below the sensitivity limits of the technique.

\subsection{Analysis of hydrogen implanted samples (no helium damage)}

In order to investigate the role of radiation damage in the trapping of hydrogen in metals one must first examine the trapping of hydrogen in undamaged samples. The analyses of samples implanted with hydrogen at 10,15 , and $20 \mathrm{keV}$ to doses of $6 \times 10^{16}$ $\mathrm{H} / \mathrm{cm}^{2}$ are shown in figs. $2-4$, respectively. The cal. culated implantation and damage distributions accord.

Table 1

He and $H$ implantations and fraction of $H$ trapped in samples represented by figs. 2 to 4 and 6 to 10 .

\begin{tabular}{|c|c|c|c|c|c|}
\hline \multirow{2}{*}{$\begin{array}{l}\text { Figure } \\
\text { number }\end{array}$} & \multicolumn{2}{|c|}{ Helium implantation } & \multicolumn{2}{|c|}{ Hydrogen implantation } & \multirow{2}{*}{$\begin{array}{l}\text { \% } 1 \text { ydrogen trapped } \\
\text { between } 40 \text { and } 200 \text { nm }\end{array}$} \\
\hline & $\begin{array}{l}\text { Energy } \\
(\mathrm{keV})\end{array}$ & $\begin{array}{l}\text { Concentration } \\
\left(10^{16} \mathrm{He} / \mathrm{cm}^{2}\right)\end{array}$ & $\begin{array}{l}\text { Energy } \\
(\mathrm{keV})\end{array}$ & $\begin{array}{l}\text { Concentration } \\
\left(10^{16} \mathrm{H} / \mathrm{cm}^{2}\right)\end{array}$ & \\
\hline 2 & & & 10 & 6.0 & 9.2 \\
\hline 3 & & & 15 & 6.0 & 16.0 \\
\hline 4 & & & 20 & 6.0 & 20.0 \\
\hline $6 \mathrm{~B}$ & 18 & 1.0 & 10 & 6.0 & 36.0 \\
\hline $6 \mathrm{C}$ & 18 & 1.0 & 10 & 10 & 32.0 \\
\hline $7 \mathrm{~A}$ & 150 & 8.0 & 10 & $\mathbb{1} .0$ & 85.0 \\
\hline $7 \mathrm{~B}$ & 150 & 8.0 & 10 & 2.0 & 89.0 \\
\hline $7 \mathrm{C}$ & 150 & 8.0 & 10 & 6.0 & 37.0 \\
\hline 8 & 150 & 8.0 & 20 & 6.0 & 39.0 \\
\hline
\end{tabular}




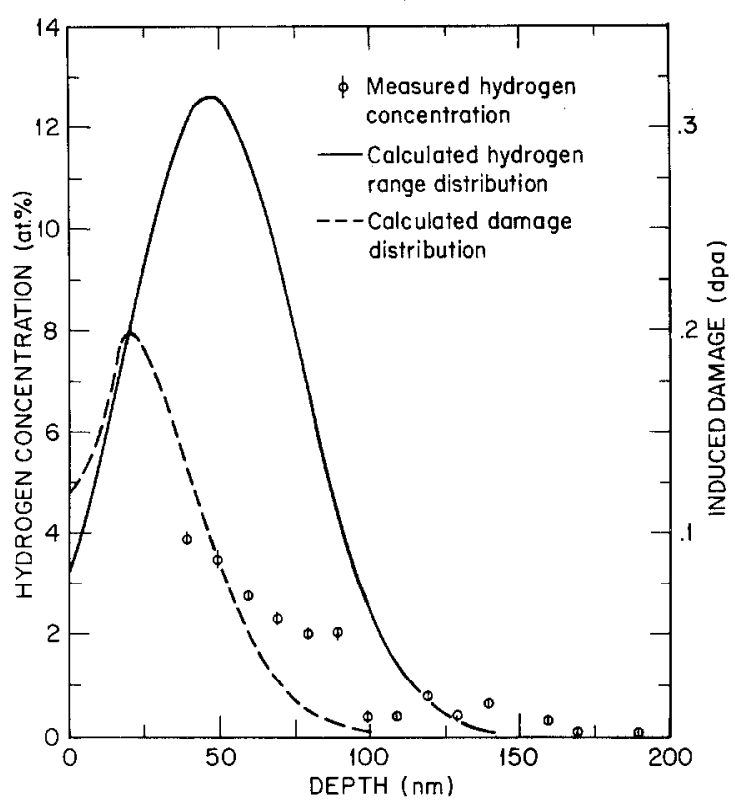

Fig. 2. Hydrogen depth profile in single crystal molybdenum after implantation of $6 \times 10^{16} \mathrm{H} / \mathrm{cm}^{2}$ at $10 \mathrm{keV}$. Shown also are the calculated range and damage distributions for $10-\mathrm{keV}$ hydrogen ions.

ing to Brice Code predictions [22] using stopping power data from [23] are shown for comparison in the same figures. The distributions show trapping

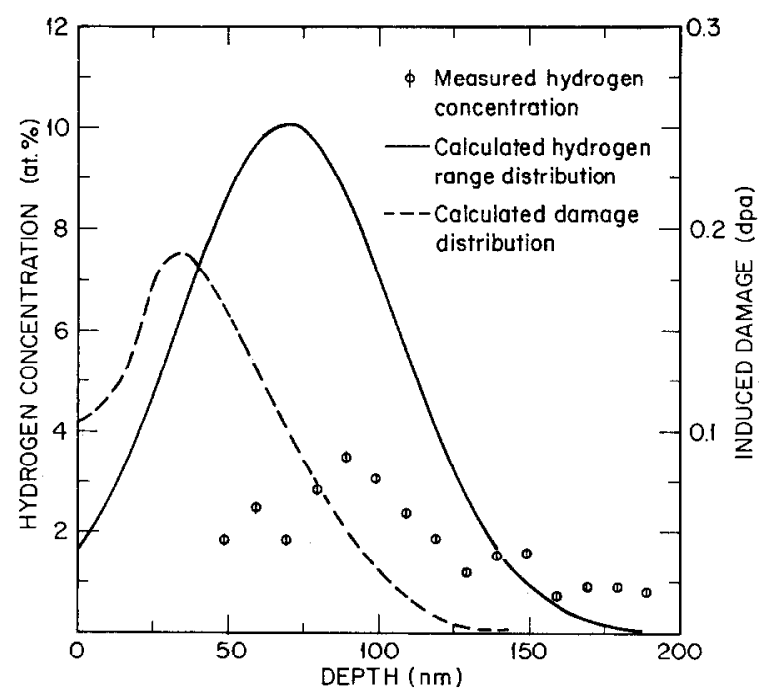

Fig. 3. Hydrogen depth profile in single crystal molybdenum after implantation of $6 \times 10^{16} \mathrm{H} / \mathrm{cm}^{2}$ at $15 \mathrm{keV}$. Shown also are the calculated range and damage distributions for $15 \mathrm{keV}$ hydrogen ions.

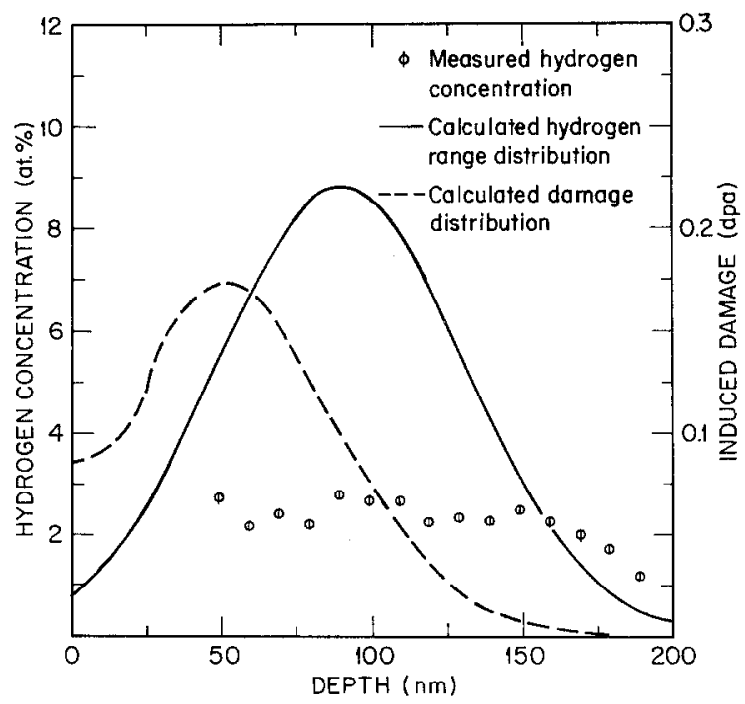

Fig. 4. Hydrogen depth profile in single crystal molybdenum after implantation of $6 \times 10^{16} \mathrm{H} / \mathrm{cm}^{2}$ at $20 \mathrm{keV}$. Shown also are the calculated range and damage distributions for $20-\mathrm{keV}$ hydrogen ions.

efficiencies of 9,16 , and $20 \%$ for the 10-, 15-, and $20-\mathrm{keV}$ hydrogen implants, respectively, between 40 and $200 \mathrm{~nm}$. According to Brice Code predictions the amount of hydrogen that should come to rest in this portion of the sample is $28 \%$ for the $10-\mathrm{keV}$ implant, $52 \%$ for the $15 \mathrm{keV}$ implant, and $69 \%$ for the $20 \mathrm{keV}$ implant. The ratio of the amount of hydrogen detected to the amount of coming to rest between 40 and $200 \mathrm{~nm}$, according to Brice Code predictions, is remarkable constant. This ratio is $0.32,0.31$ and 0.29 for the $10-, 15-$ and $20-\mathrm{keV}$ implants, respectively.

The error bars in the figures represent only the statistical uncertainties in the gamma-ray yields as given in $[7,13]$. The errors associated with the Amsel et al. cross section data [16] have been neglected. The counting statistics of those data are extremely good and would be overwhelmed by the errors from the data of the present experiment. The error associated with the stopping power of fluorine incident on molybdenum will produce an uncertainty in the depth of each point included in the figures. This uncertainty is ignored since the stopping power must be interpolated from the Northcliffe and Schilling tables, and the uncertainties in the data and interpolations are not available. 


\subsection{Discussion of the helum predamage}

Most of the samples studied were damaged with 18 and $150 \mathrm{keV}$ helium prior to the hydrogen implanta. tion. The reasons for selecting helium for the pro. duction of damage were threefold. First, the implantation of helium in metals and alloys is of interest in fusion and fission technologies. Second, the "selftrapping" of helium, that is, the trapping of helium in the presence of the radiation damage that is produced during its own implantation, is virtually 100\%. This helium is tightly bound to the vacancies, requiring high temperature anneals to dislodge it $[24-26]$. Therefore, relocation of the helium during the experiment could be neglected. Third, it was desired to be able to achieve both high and low ratios of damage levels to implantation species. Since the energy limit of the accelerator used for the implan. tations was $150 \mathrm{keV}$, the achievement of the high ratio is not possible with heavier ions.

There were a number of reasons for selecting 18 $\mathrm{keV}$ as one of the helium implantation energies. First; this was an energy selected by Bottiger et al. [6], so some of our results can be compared to previously

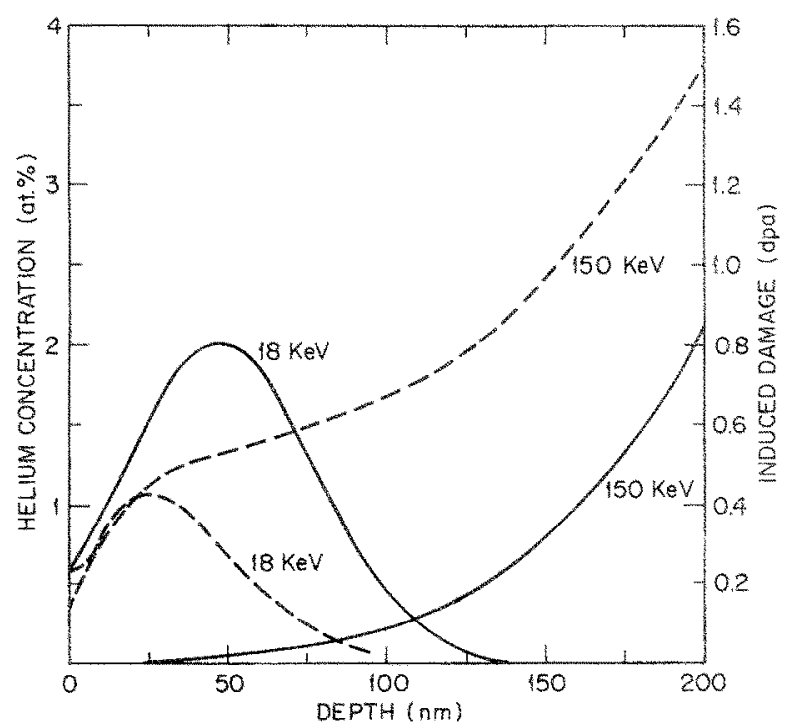

Fig. 5. Brice Code calculations for the implantation distributions (solid line) and the damage distributions (dashed line) for helium incident on molybdenum at $150 \mathrm{keV}$ to a dose of $8 \times 10^{16} \mathrm{He} / \mathrm{cm}^{2}$ and for helium incident on molybderum at $18 \mathrm{keV}$ to a dose of $1 \times 10^{16} \mathrm{He} / \mathrm{cm}^{2}$. published data. Second, the entre hetum distrbmion lies within the limits of the hydrogen amalyms tach. nique employed in this experinaten. Ther the ratio of helum concentration to danage level is high for our region of interest compared to the $150 \mathrm{keV}$ implant.

Fig. 5 shows the helium implantation and danage distributions as calculated by the Brice Code 122 using stopping power data from the complation by Ziegler [27]. It should be noted that the damage dis. tribution calculation from the Brice cole resuls from solving cnergy deposinon equators cenpled with the modifed Kinchin and pease nodel. These calculations do not take recombination of the refects into account. Therefore the dpa quoted are only the number of displacement intrally produced $728 \mathrm{~m}$ 311.

The dose of $8 \times 10^{16} \mathrm{He} / \mathrm{cm}^{3}$ for the $150 \mathrm{keV}$ helum implantation was selected so that the damage density at $25 \mathrm{~nm}$ was equal to the maximum in the damage distribution resulting from the implantation of $1 \times 10^{16} \mathrm{He} / \mathrm{cm}^{2}$ at $18 \mathrm{keV}(\mathrm{fg}, 5)$. As can be seen from ng. 5 , the maximum in whe danage distributhon resulting from implantation of the $18 \mathrm{keV}$ helum was calculated to occur at $25 \mathrm{~nm}$ and produced $0.46 \mathrm{dpa}$. At the same depth, the damage level resulting from the $150 \mathrm{keV}$ implan was 0.49 apa.

\subsection{Hydrogen implantations in samples predanaged with 18 kel helium}

Fig. 6 shows hydrogen profiles (B) and $(C)$ in samples predamaged with $1 \times 10^{2} \mathrm{He} / \mathrm{cm}^{2}$ at 18 $\mathrm{keV}$. For comparison, the profle of fig. 2 for a nonpredamaged sample is included $(A)$. The hycro gen implantation energy is the same (10 keV) for all three samples.

Compare first the lower two distributions (A) and (B)) which were implanted whth hydrogen to the same surface dose, $6 \times 10^{16} \mathrm{H} / \mathrm{cm}^{2}$. The anount of hydrogen trapped between 40 and $200 \mathrm{~mm}$ increased from $9 \%$ for the non predamaged sample to $36 \%$ for the predamaged sample. It is also interesting to note that hydrogen trapping occurs at greater depth in the damaged samples. In fact, for profle (B), the hydrom gen trapped in the region between 100 and $200 \mathrm{~nm}$ (where essentially no hydrogen is trapped in the nonpredamaged sample) amounts to $14 \%$ of the 


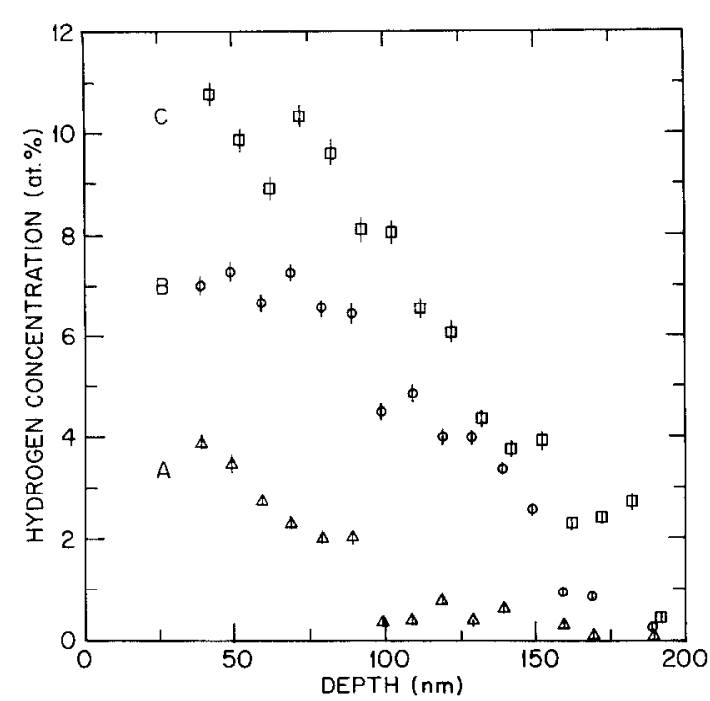

Fig. 6. Hydrogen depth profiles in single crystal molybdenum: (A) After implantation of $6 \times 10^{16} \mathrm{H} / \mathrm{cm}^{2}$ at $10 \mathrm{keV}$, reproduced from fig. 2 . (B) After predamage with $1 \times 10^{16}$ $\mathrm{He} / \mathrm{cm}^{2}$ at $18 \mathrm{keV}$ followed by the implantation of $6 \times 10^{16}$ $\mathrm{H} / \mathrm{cm}^{2}$ at $10 \mathrm{keV}$. (C) After predamage with $1 \times 10^{16}$ $\mathrm{He} / \mathrm{cm}^{2}$ at $18 \mathrm{keV}$ followed by the implantation of $1 \times 10^{17}$ $\mathrm{H} / \mathrm{cm}^{2}$ at $10 \mathrm{keV}$.

implanted hydrogen. Not only is distribution (B) deeper than the distribution arising from the hydrogen implantation in undamaged samples, it is also decper than the calculated helium implantation shown in fig. 5 . The calculated helium implantation distribution drops to half of its maximum value at 85 $\mathrm{nm}$, while the depth at which the analyzed hydrogen distribution. from the damaged sample drops to half its peak value is $130 \mathrm{~nm}$. B $\phi$ ttiger et al. [6] also made the observation that their hydrogen distributions were deeper thar expected. Deviations between the calculated and measured distributions may be explained as (1) inaccuracies in the Brice Code calculation and/or the stopping power data used in the calculations; and (2) channeling effects. This experiment demonstrates not only the enhancement of hydrogen trapping by helium predamage, but also the fact that some of the hydrogen diffused beyond its implantation range only to be trapped at deeper lying trapping sites. This will become even more evident from the examination of the results obtained with samples predamaged with $150-\mathrm{keV}$ helium ions.

B $\phi$ ttiger et al. [6], measured the trapping efficiency for deuterium in a damaged lattice. Using
$1 \times 10^{16} \mathrm{He} / \mathrm{cm}^{2}$ at an energy of $11 \mathrm{keV}$ and $6 \times$ $10^{16} \mathrm{D} / \mathrm{cm}^{2}$ at $8 \mathrm{keV}$, they measured a trapping efficiency of $67 \%$. Since they were not bothered with a large deuterium contamination layer, they were able to measure the entire amount of deuterium trapped in the sample, however, without obtaining the deuterium distribution. In contrast, we could measure hydrogen only between 40 and 200 $\mathrm{nm}$. Because of this difference in the analysis boundaries the $36 \%$ trapping measured in our experiment may be in reasonable agreement with the $67 \%$ measured by $\mathrm{B} \phi t$ tiger et al.

Profile (C) in fig. 6 was obtained by increasing the amount of implanted hydrogen from $6 \times 10^{16}$ to $1 \times 10^{17} \mathrm{H} / \mathrm{cm}^{2}$. Increasing the hydrogen implantation dose $67 \%$ increased the amount trapped $48 \%$ without significantly changing the distribution. B $\phi$ ttiger et al. observed only a $28 \%$ increase in the trapped deuterium under similar circumstances. Again the difference may be due to the fact that this experiment only measured a portion of the distribution, while $B \phi t$ tiger et al. measured the entire amount of deuterium.

\subsection{Hydrogen implantation in samples predamaged with $150 \mathrm{keV}$ helium}

A large fraction of the samples studied had been damaged with $150 \mathrm{keV}$ helium to a dose of $8 \times 10^{16}$ $\mathrm{He} / \mathrm{cm}^{2}$ prior to the hydrogen implantation. Fig. 7 shows hydrogen profiles for three of these samples. The hydrogen implantation energy is again 10 $\mathrm{keV}$ for all three implants, but the hydrogen dose varies: Profile (A) represents an implantation dose of $1 \times 10^{16} \mathrm{H} / \mathrm{cm}^{2}$, while the doses for (B) and (C) are $2 \times 10^{16}$ and $6 \times 10^{16} \mathrm{H} / \mathrm{cm}^{2}$, respectively.

An obvious and significant feature obscrvable in fig. 7 is the saturation of traps. When the hydrogen implantation dose was increased from $1 \times 10^{16}$ $\mathrm{H} / \mathrm{cm}^{2}$ (profile (A)) to $2 \times 10^{16} \mathrm{H} / \mathrm{cm}^{2}$ (profile (B)), the amount of hydrogen trapped doubled without significantly changing the shape of the distributions nor the percentage trapped (table 1). However, when the dose was increased from $2 \times 10^{16}$ to $6 \times 10^{16} \mathrm{H} / \mathrm{cm}^{2}$, the percentage of total hydrogen trapped fell from 80 to $37 \%$. More interesting though, the increase in hydrogen concentration was confined mainly to the region bounded by 140 and $200 \mathrm{~nm}$, 


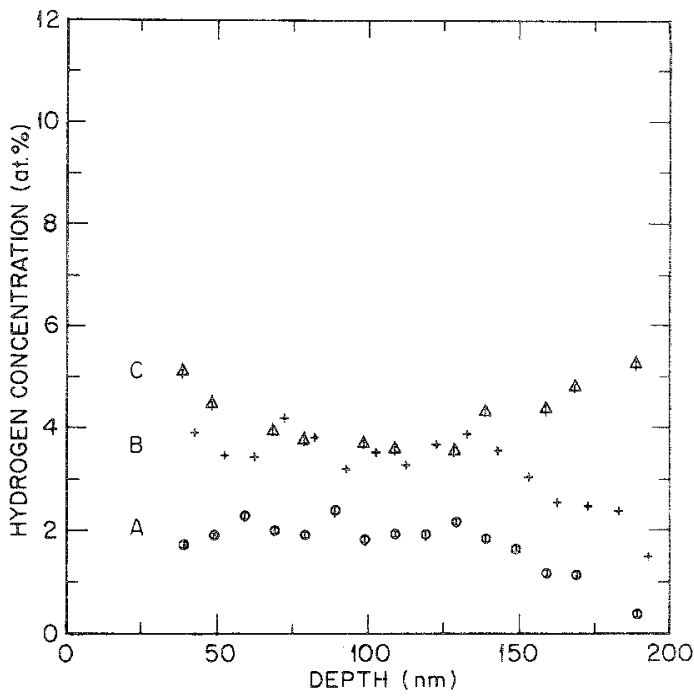

Fig. 7. Hydrogen depth profile in single crystal molybdenum after predamage with $8 \times 10^{16} \mathrm{He} / \mathrm{cm}^{2}$ at $150 \mathrm{keV}$ followed by the implantation of (A) $1 \times 10^{16} \mathrm{H} / \mathrm{cm}^{2}$ at $10 \mathrm{keV}$, (B) $2 \times 10^{16} \mathrm{H} / \mathrm{cm}^{2}$ at $10 \mathrm{keV},(\mathrm{C}) 6 \times 10^{16} \mathrm{H} / \mathrm{cm}^{2}$ at $10 \mathrm{keV}$.

where the increase was $43 \%$. This should indicate a saturation of traps with hydrogen in the first 130 nim.

The distributions shown in fig. 7 can be divided into two regions: the "near" (40 to $100 \mathrm{~nm}$ ) region

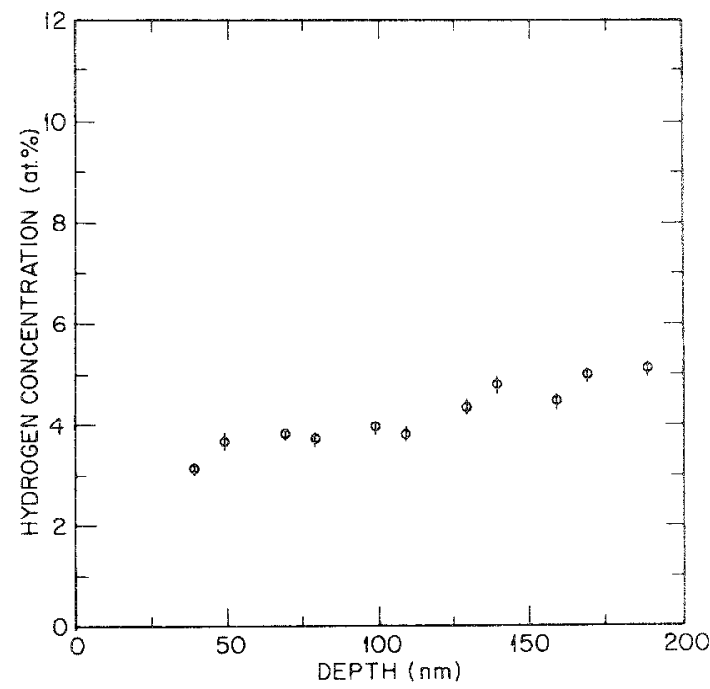

Fig. 8. Hydrogen depth profile in single crystal molybdenum after predamage with $8 \times 10^{16} \mathrm{He} / \mathrm{cm}^{2}$ at $150 \mathrm{keV}$ followed by the implantation of $6 \times 10^{16} \mathrm{H} / \mathrm{cm}^{2}$ at $20 \mathrm{keV}$. and the "far" (100 to $200 \mathrm{~nm}$ ) region. The implanted hydrogen comes to rest in the near region of the sample and then must migrate to the fa: region. The decrease with depth of the hydrogen concentration in the near region notable in profle (C) is probably dre to the "self-trapping" mentioned previously. This assumption is supported by the profle showe in fig. 8 which differs from profle (C) in fig. 7 only in the hydrogen implantation energy which was increased to $20 \mathrm{keV}$ for the sample of ng. 8 . The saddle shape noticeable in profile (C) of fig. 7 is no longer observed in the profile of fig, 8 while the total amount of hydrogen trapped between 40 and $200 \mathrm{~nm}$ did not change appreciably, which is another confirmation of the saturation of traps with hydrogen mer. tioned earlier. The increase with depth of trapped hydrogen in the far region of the samples with the highest hydrogen implantation dose (profile (C) of fig. 7 and fig. 8) shows an increase in the trapping efficiency due to higher damage levels and/or higher helium concentration.

Since the information in fig. 7 indicates that radia. tion damage produced by the implantation of the 10-keV hydrogen influences the shape of the trapped hydrogen distribution in the first $100 \mathrm{~nm}$, an examination of the amount of hydrogen trapped at $110 \mathrm{~nm}$ is of interest then for several reasons: (I) the hydrogen trapped here is beyond the region of hydrogen self-trapping; (2) the hydrogen trapping

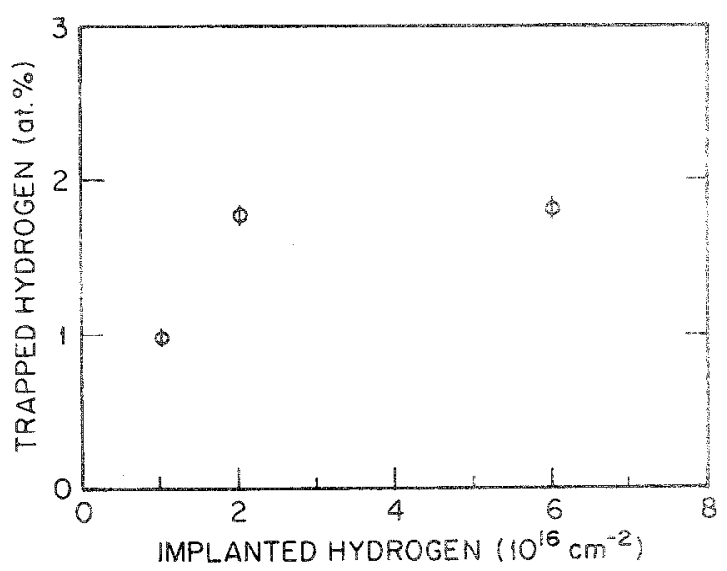

Fig. 9. Amount of hydrogen trapped at 10 nm as a function of implanted hydrogen dose. This illustrates the saturation of traps with hydrogen at this point when the sample was damaged with $8 \times 10^{16} \mathrm{He} / \mathrm{cm}^{2}$ at $150 \mathrm{keV}$. 
should be saturated when the hydrogen implantation dose is $6 \times 10^{16} \mathrm{H} / \mathrm{cm}^{2}$; and (3) the helium concentration is still relatively low. At this point, when saturation has been attained, the hydrogen concentration is 1.8 at $\%$. Fig. 9 illustrates the saturation of the traps at $110 \mathrm{~nm}$ by plotting the trapped hydrogen concentration as a function of hydrogen implantation dose. The Brice Code calculations show the helium concentration at $110 \mathrm{~nm}$ is 0.28 at $\%$ and the induced damage is $0.72 \mathrm{dpa}$. This leads to ratios of 6.4 hydrogen atoms trapped per helium atom and 0.025 hydrogen atoms trapped per initially displaced lattice atom. These numbers are given as an illustration of the effectiveness of helium implantations in the creation of hydrogen traps. They must, however, be considered as tentative for the following reasons: Both the helium concentrations and the number of displacements per atom are the result of calculations whose validity is in doubt in the portion of the distributions that were of interest for this experiment, even though the projected range of the implanted particles may be accurate.

\subsection{Hydrogen implantation in samples annealed after predamage with 18 and $150 \mathrm{keV}$ helium}

B $\phi$ tiger et al. [6] annealed several molybdenum samples after implantation with $1 \times 10^{15} \mathrm{Ne} / \mathrm{cm}^{2}$ at $55 \mathrm{keV}$ prior to the introduction of deuterium at 8 $\mathrm{keV}$ to doses of $3 \times 10^{15}, 3 \times 10^{16}$, and $5 \times 10^{16}$ $\mathrm{D} / \mathrm{cm}^{2}$. The annealings were at $300^{\circ} \mathrm{C}$ for ten minutes, noting that stage III annealing begins around $250^{\circ} \mathrm{C}[32,33]$. Those authors found no net loss of traps after this anneal.

Two of our samples were also annealed at $300^{\circ} \mathrm{C}$ for ten minutes after implantation of $8 \times 10^{16}$ at 150 $\mathrm{keV}$ and $1 \times 10^{16} \mathrm{He} / \mathrm{cm}^{2}$ at 18 at $\mathrm{keV}$ prior to the implantation of $6 \times 10^{16} \mathrm{H} / \mathrm{cm}^{2}$. Very few differences were noted between the distributions of the annealed and unannealed samples with the exception that there was a $25 \%$ gain in the amount of hydrogen trapped in the $18 \mathrm{-keV}$ helium implanted annealed sample. One possible source for the extra hydrogen is from the diffusion of surface hydrogen into the sample during the anneal.

\section{Discussion}

\subsection{The study of nonpredamage samples}

From studying the samples implanted with only hydrugen (figs. 2-4) it becomes obvious that the amount of damage which the hydrogen produces during its implantation results in a significant amount of trapping, which has been referred to as "self-trapping". The $10-\mathrm{keV}$ hydrogen implant produces no significant trapping beyond the first $100 \mathrm{~nm}$. However, the trapped hydrogen distributions resulting from the 15- and $20-\mathrm{keV}$ implants extend over the entire region of analysis (40 to $200 \mathrm{~nm}$ ). The fact that hydrogen implanted at $10 \mathrm{keV}$ does not "selftrap" appreciably beyond $100 \mathrm{~nm}$ is important since it permits the conclusion that any hydrogen trapped in the 100 to $200 \mathrm{~nm}$ region of the sample, when the sample was predamaged, was the result of the predamage. Certainly from this point of view, hydrogen implantation energies less than $10 \mathrm{keV}$ would have been preferred, but $10 \mathrm{keV}$ was the lowest energy attainable for hydrogen implantations with the accelerator used.

\subsection{The study of samples predamaged with $150 \mathrm{keV}$ helium}

The comparison of the trapped hydrogen (implanted at $10 \mathrm{keV}$ to a dose of $6 \times 10^{16} \mathrm{H} / \mathrm{cm}^{2}$ ) in samples that had not been predamaged (fig. 2) to samples that had been predamaged with $8 \times 10^{16}$ $\mathrm{He} / \mathrm{cm}^{2}$ at $150 \mathrm{keV}$ (curve (C) of fig. 7) shows an increase in the hydrogen trapping from 9.2 to $37 \%$ between 40 and $200 \mathrm{~nm}$. Close examination of these distributions shows that the hydrogen concentration at any point within the first $90 \mathrm{~nm}$ of the sample increased by no more than a factor of 2.5 aftcr the predamage. The amount of hydrogen trapped in the deeper portion of the sample increased from being negligible to being on the order of the amount trapped in the first $90 \mathrm{~nm}$. Clearly some of the hydrogen that comes to rest in the first $100 \mathrm{~nm}$ is relatively free to migrate to other portions of the sample where it can be trapped. The fact that the hydrogen distribution of curve (C) of fig. 7 extends well beyond the region of the sample where the hydrogen comes to rest suggests that the traps may reach a saturation with hydrogen. 


\subsection{The study of samples predamaged with $18 \mathrm{keV}$ helium}

In the sample that had been predamaged with 18 $\mathrm{keV}$ helium to a dose of $1 \times 10^{16} \mathrm{He} / \mathrm{cm}^{2}$ and then implanted with $6 \times 10^{16} \mathrm{H} / \mathrm{cm}^{2}$ at an energy of 10 $\mathrm{keV}$, the amount of hydrogen that is trapped between 40 and $100 \mathrm{~nm}$ (3.6 at\% maximum) is 50 to $100 \%$ higher than the amount of hydrogen trapped in the samples damaged with $150 \mathrm{keV}$ helium. This happens even though the damage levels at $25 \mathrm{~nm}$, where the damage distribution from the $18 \mathrm{keV}$ helium implant peaks, were calculated to be the same. Another interesting observation was that when the hydrogen dose was increased to $1 \times 10^{17} \mathrm{H} / \mathrm{cm}^{2}$, for the $18-\mathrm{keV}$ helium predamage, the amount of trapped hydrogen increased $48 \%$ (peaking at 5.2 at $\%$ ) without changing the shape of the distribution. Clearly the saturation of traps with hydrogen that was observed with the $150 \mathrm{keV}$ helium predamage has not been observed yet with the predamage from the $18 \mathrm{keV}$ helium implant even though the calculated number of induced displacements per atom was at or below the number produced by the $150 \mathrm{keV}$ helium implant. Obviously, the number of displacements per atom (dpa) is not a good measure of the permanent damage induced by the helium bombardment. At least, as far as our observable (the concentration of hydrogen traps) is concerned, the permanent damage is a function of the number of helium atoms that come to rest within the range of observation.

\section{Conclusions}

The conclusions that can be drawn from the experimental results can be divided into three major groups:

(1) It was shown that damage of the samples with helium (when no hydrogen was implanted) does not create a significant level of hydrogen in the near surface region of the sample.

(2) A saturation of the traps with hydrogen was clearly in evidence when the samples were damaged by the implantation of $8 \times 10^{16} \mathrm{He} / \mathrm{cm}^{2}$ at $150 \mathrm{keV}$ prior to the implantation of hydrogen at $10 \mathrm{keV}$ to a dose of $6 \times 10^{16} \mathrm{H} / \mathrm{cm}^{2}$. However, saturation of traps with hydrogen apparently had not yet been attained when the samples were predanaged with $1 \times 10^{\text {th }}$ He/ $\mathrm{cm}^{2}$ at $18 \mathrm{keV}$ even though the level of trapping was on the order of a factor of two higher for the 18-keV helium predamage. The damage levels result. ing from these helium implantations were calculated to be the same at the peak in the $18 \mathrm{keV}$ helium damage.

(3) The implanted helium contributes to the trapping of hydrogen possibly through the inhibition of danage anmealing. The fact that helium does not detrap significantly until high temperatures $[26-26]$ means that this inhibition may be significant well beyond temperatures used in this experiment.

The trapping of hydrogen in metals in which the hydrogen is mobile shows promise for use in the study of damage processes in these metals. Hould be particularly useful in the study of radiation damage where most or all of the damage can be con. fincd to a region of the sample that can be studied with the analysis technique being utilized. In this experiment the hydrogen was introduced by implan. tation at $10 \mathrm{keV}$. However, the results of simular experiments would lend themselves more easily to interpretation if the hydrogen energy were to be lowered since the implantation of the hydrogen produces a significant amount of danage which leads to some "self-trapping". The self-trapping from the 10-keV hydrogen implantation used in this experiment extended to almost one-half of the entire region that can be explored with the fluorine 19 probe.

\section{Acknowledgements}

The help of John S. King and Wiliam G. Halsey in planning and assembling the ion implantation facility, in data taking (W.G.H.) and in discussing the results obtained has been invaluable. One of us (A.L.H.) is indebted to the Argonne Center of Educational Affairs for a Thesis Parts Appointment.

We also thank the Physics Department of Western Michigan University, particulariy S.M. Ferguson and E.M. Bernstein, for the use of their accelerator for part of the ion heam analysis work. The University of Michigan supported our work through a number of internal grants. This work was performed in part under the auspices of the US Department of Energy 


\section{References}

[1] Hydrogen Damage, Ed, C.D. Beachen (American Society for Metals, Metals Park, $\mathrm{OH}, 1977$ ).

[2] I.M. Bernstein and A.W. Thompson, Int. Met. Rev., Rev. No. 212 (1976) 269.

[3] D.A. Leich and T.A. Tombrello, Nucl. Instrum. Meth. 108 (1973) 67.

[4] E. Ligeon and A. Guivarc'h, Radiation Effects 22 (1974) 101.

[5] P.P. Pronko, J. Nucl. Mater. 53 (1974) 252;

P.P. Pronko and J.G. Pronko, Phys. Rev. B9 (1974) 2870.

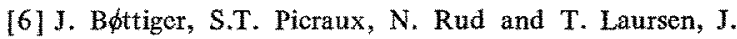
Appl. Phys. 48 (1977) 920. (See also [11,12])

[7] G.J. Clark, C.W. White, D.D. Allred, B.R. Appleton, F.B. Koch and C.W. Magee, Nucl. Instrum. Meth. 149 (1978) 459.

[8] W.A. Lanford, Nucl. Instrum. Meth. 149 (1978) 1.

[9] S.K. Erents and G.M. McCracken, Brit. J. Appl. Phys. Ser. (J. Phys. D) 2 (1969) 1397; Radiation Effects 3 (1970) 123 .

[10] G.M. McCracken and S.K. Erents, in: Applications of Ion Beams to Metals, Eds. S.T. Picraux, E.P. EerNisse, and F.L. Vook (Plenum, New York, 1974) p. 585.

[11] S.T. Picraux, J. Bottiger and N. Rud, I. Nucl. Mater. 63 (1976) 110 .

[12] S.T. Picraux, J. B $\phi$ ttiger and N. Rud, Appl. Phys. Letters 28 (1976) 179.

[13] A.L. Hanson, University of Michigan, Dissertation (1979).

[14] D. Dieumegard, B. Maurel and G. Amsel, Nucl. Instrum. Meth. 168 (1980) 93.

[15] F. Ajzenberg-Selove, Nucl. Phys. Al40 (1972) 1.

[16] G. Amsel and B. Maurel, private communication.

[17] J.P. Bugeat and E. Ligeon, Nucl. Instrum. Meth. 159 (1979) 117.

[18] E.J. Williams, Proc. Roy. Soc. (London) A135 (1932) 108 .
[19] R.B. Strittmatter and B.W. Wehing, Nucl. Instrum. Meth. 135 (1976) 173.

[20] L.C. Northcliffe and R.F. Schilling, Nucl. Data Tables A7 (1970) 233.

[21] W.K. Chu, in: Ion Beam Handbook for Material Analysis, Eds. J.W. Mayer and E. Rimini (Academic Press, New York, 1977) p. 10.

[22] D.K. Brice, SAND-75-0622 (Computer Codes: COREL, RASE4, and DAMG2).

[23] H.H. Andersen and J.F. Ziegler, Hydrogen: Stopping Powers and Ranges in all Elements, Vol. 3 of The Stopping and Ranges of Ions in Matter (Pergamon, New York, 1977).

[24] J.P. Biersack, D. Fink, P. Mertens, R.A. Henkelmann and K. Müller, in: Proc. Intern. Symp. on Plasma Wall Interactions (Pergamon, Oxford, 1977) p. 421.

[25] J.P. Biersack, D. Fink, R.A. Henkelmann and K. Müller, J. Nucl. Mater. 85/86 (1979) 1165.

[26] W.G. Halsey, University of Michigan, Dissertation (1980).

[27] J.F. Ziegler, Helium: Stopping Powers and Ranges in All Elemental Matter, Vol. 4 of The Stopping and Ranges of lons in Matter (Pergamon, New York, 1977).

[28] C. Lehmann, Interaction of Radiation with Solids and Elementary Defect Production, Vol. 10 of Defects in Crystalline Solids, Eds. S. Amelinckx, R. Gevers and J. Nihoul (North-Holland, Amsterdam, 1977).

[29] I.M. Torrens and M.T. Robinson, in: Radiation Induced Voids in Metals, Eds. J.W. Corbett and L.C. Ianniello, CONF-710601 (USAEC, 1972) p. 739.

[30] I.M. Torrens and M.T. Robinson, in: Interatomic Potentials and Simulation of Lattice Defects, Eds. P.C. Gehlen, J.E. Beeler and R.I. Jaffee (Plenum, New York, 1972) p. 423 .

[31] P. Sigmund, Radiation Effects 1 (1969) 15.

[32] M. Eldrup, O.E. Mogensen, and J.H. Evans, J. Phys. F (Metal Phys.) 6 (1976) 499.

[33] R.S. Reintsema, J. Odeurs, E. Verbiest, H. Pattyn and R. Coussement, Hyperfine Interactions 4 (1978) 685. 